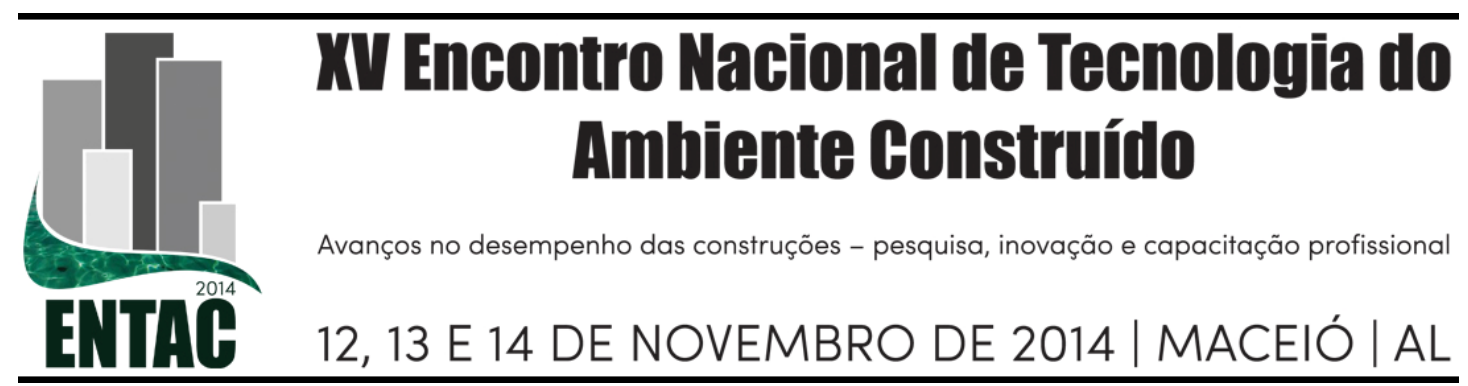

\title{
GESTÃo DE PROJETOS NA CONSTRUÇÃO CIVIL: AVALIAÇÃO DO PROCESSO EM EMPRESAS CONSTRUTORAS DE FLORIANÓPOLIS
}

\author{
AVILA, Ticiana (1), MUTTI, Cristine (1), OLIVEIRA, Roberto (2), \\ LIBRELOTTO, Lisiane (2)
}

(1)Universidade Federal de Santa Catarina - Departamento de Engenharia Civil, email: ticiana.frigo@ufsc.br (2) Universidade Federal de Santa Catarina - Departamento de Engenharia Civil, email: cristine_mutti@yahoo.co.uk (3) Universidade Federal de Santa Catarina - Departamento de arquitetura e Urbanismo, email: rdeoliveirabr@hotmail.com (4) Universidade Federal de Santa Catarina-

Departamento de arquitetura e Urbanismo, email: lisiane.librelotto@gmail.com

\begin{abstract}
RESUMO
Este artigo apresenta a avaliação do processo de gestão de projetos, como resultado de uma pesquisa conduzida em dissertação de mestrado, em duas empresas de construção e incorporação de Florianópolis. Por considerar as melhores práticas observadas em modelos clássicos da bibliografia, relativas ao processo de gestão de projeto de edificações, o modelo base adotado nesta pesquisa foi o Modelo de Processo Integrado de Edificações (GPPIE), proposto por (Romano, 2003). O modelo também aborda preceitos referentes à área de Gerenciamento de Projetos e de Desenvolvimento Integrado de Produtos como, por exemplo: o trabalho em equipe multidisciplinar; o desenvolvimento simultâneo de atividades do processo; o desenvolvimento dos projetos para produção e projetos do produto; a designação do gerente para coordenar o processo de projeto desde o início do mesmo; utilização de práticas gerenciais e instrumentos para a melhoria da qualidade do projeto. Os resultados indicam que os modelos de gestão do processo de projeto presentes na literatura não se aplicam diretamente ao universo das empresas estudadas, necessitando sempre de ajustes ao cotidiano das mesmas. Isto porque as empresas de uma maneira geral, estão sujeitas às oscilações do mercado, criadas pela necessidade de adaptação, em função de interferências externas (projetistas, clientes, financiadores, legislação, entre outros). Muitos fatores, de diferentes naturezas, são aqui apresentados e debatidos.
\end{abstract}

Palavras-chave: Projetos de edificações, Coordenação, Compatibilização.

\begin{abstract}
This paper presents an evaluation of the project management process, as a result of a research conducted for a master's degree. The study involves two building companies in Florianópolis. The model adopted here is the 'Model of Integrated Processes in Buildings' ( GPPIE ) proposed by (Romano, 2003), because it included the best practices observed in classic models in the literature about project management process of the building design. The result indicates that the models available do not directly apply to the companies studied. They require adjustments to the routine of these companies. This is due to the fact that building companies in general are subject to market fluctuations, created by the need to adapt, due to external interference (designers, clients, funders, law, etc.). Many features of different natures are here presented and discussed.
\end{abstract}

Keywords: building projects, coordination, compatibility 


\section{INTRODUÇÃO}

Considerando-se que o projeto de uma edificação é desenvolvido pela interação entre várias especialidades e, mesmo o processo de produção do empreendimento sendo resultado da participação de diversos outros agentes, a realidade do projeto envolve uma extensa lista de condicionantes e atributos. Soluções visando a construtibilidade, a racionalização do processo, assim como a busca por sistemáticas para aumento da produtividade e redução de custos são primordiais para a sobrevivência empresarial. As dimensões e formas do terreno, a legislação urbana, os sistemas construtivos-tecnológicos e as imposições mercadológicas, exigem a máxima ocupação possível e constituem-se nas principais restrições apresentadas aos arquitetos a serem consideradas na concepção (Adesse, 2003). (Melhado, 1998) afirma que a qualidade de projeto será sempre fruto de vários fatores, tanto intrínsecos quanto extrínsecos. São fatores intrínsecos: a competência dos profissionais; a existência de profissionais especializados para problemas específicos; a padronização da apresentação das informações; a observação às necessidades do empreendedor; a consideração das necessidades da produção e controle; a coordenação das atividades e controle das interfaces. São considerados fatores extrínsecos: a qualidade da incorporação e comercialização; a normalização adequada - critérios de projeto e dimensionamento, conteúdo e apresentação dos projetos; acesso ao conjunto de informações técnicas necessárias à elaboração do projeto e especificações claras e eficientes, por parte dos órgãos de aprovação, quanto às legislações aplicáveis ao caso. As construtoras enquanto contratantes, devem estabelecer princípios para as relações com os projetistas. Cabe às empresas, prover a equipe de trabalho com as definições e especificações do escopo de projeto; transmitir as informações entre os diversos agentes envolvidos no empreendimento (proprietários, projetistas, gerentes, construtores); coordenar os projetos elaborados pelos diversos profissionais; e controlar a qualidade desses projetos. Recentemente, os trabalhos de (Brasil, 2013) e (Manzione, 2013) dão ainda mais relevância à 'gestão do processo de projetos'. (Brasil, 2013) analisa os entraves dessa gestão perante a Lei 8.666/93; (Manzione, 2013) propõe uma estrutura conceitual de gestão do processo de projeto colaborativo com o uso do BIM (Building Information Modeling). Neste contexto, o presente artigo tem por objetivo geral avaliar a gestão do processo de projeto de edificações em duas empresas de construção e incorporação de imóveis na cidade de Florianópolis. Para isto, será preciso caracterizar coordenação e compatibilização de projetos na área da construção e incorporação de imóveis; definir a metodologia para avaliação das empresas participantes; mapear o processo de projeto das empresas; e por fim avaliar o processo operacional para controle e desenvolvimento do projeto em cada uma das empresas estudadas. A pesquisa, em sua totalidade, é encontrada na dissertação de mestrado de (Avila, 2010). Para a estruturação desta pesquisa foram recolhidos documentos que evidenciassem a concretização destas etapas, como por exemplo, o plano de projeto; os requisitos de projeto; o programa de necessidades; os relatórios de análise crítica, entre outros. Estes documentos foram avaliados de acordo com sua finalidade, aplicação e conteúdo. Além disso, durante o período do estudo, o processo de elaboração dos projetos de edificações de cada uma das empresas foi mapeado através de fluxograma, para o melhor entendimento do encadeamento das atividades de projeto e respectivos responsáveis. A avaliação será feita tomando-se como base o modelo de processo integrado de edificações (GPPIE) proposto por (Romano, 2003), conforme ilustra a Figura 1. A escolha por este modelo foi motivada por dois pontos principais: para manter a ética e a imparcialidade, já que a autora principal desta pesquisa, atuava como coordenador de projetos em uma das entidades participantes deste estudo; e depois, pelo modelo proposto por Romano ter sido concebido a partir da compilação das melhores práticas propostas por modelos clássicos da literatura. 
Figura 1 - As macrofases do processo de projeto

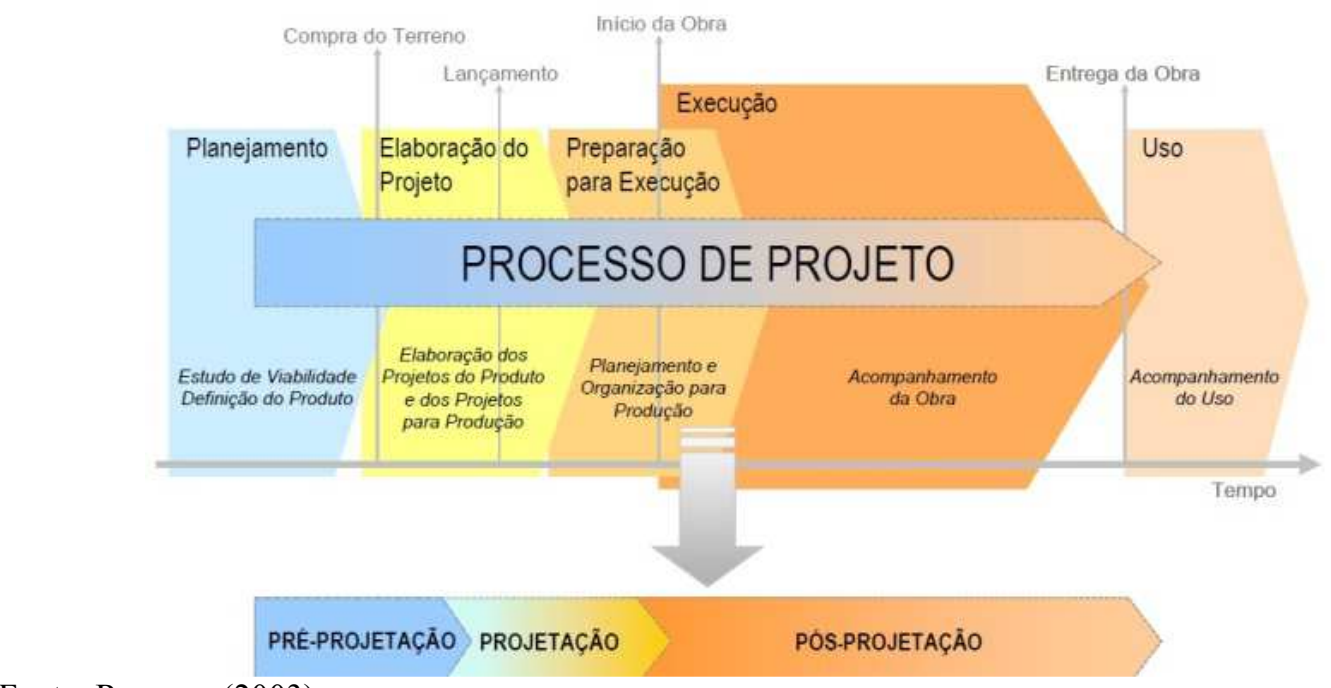

Fonte: Romano (2003)

Para análise, (Romano, 2003) propõe agrupar as informações em dois grupos. O grupo 1 trata do processo de projeto de edificações e envolve os seguintes elementos: formalização do processo de projeto; fases do processo de projeto; planejamento do empreendimento; desenvolvimento do projeto informacional da edificação; desenvolvimento do projeto conceitual da edificação; desenvolvimento do projeto preliminar da edificação; desenvolvimento do projeto detalhado e dos projetos para produção da edificação; acompanhamento da obra; acompanhamento do uso. O grupo 2, por sua vez, trata do processo de gerenciamento de projetos e inclui: iniciação; planejamento; execução; controle; e encerramento. De forma a mensurar o quanto as empresas estudadas atendem aos requisitos em análise, definiu-se uma escala numérica variando de [ $\mathrm{n} / \mathrm{a} \quad 00,50$ 1], sendo: ' 1 = atende totalmente': foram considerados aqui os critérios formalizados dentro dos processos de projeto nas empresas A e B; ' $0,5=$ atende parcialmente': foram considerados aqui os critérios atendidos, mas com informações incompletas, de forma muito simplificada, ou ainda aqueles que não estão formalizados mas são levados em consideração dentro dos processos de projeto nas empresas A e B; '0 = não atende': foram considerados aqui todos os critérios que não se encaixam nas opções anteriores, ou seja, não estão formalizados e não são levados em consideração dentro dos processos de projeto das empresas A e B; ' $\mathrm{n} / \mathrm{a}$ = não abordado': foram considerados aqui os itens que fazem parte de etapas não abordadas pelo escopo desta pesquisa.

\section{DIAGNÓSTICO DE COMPARAÇÃO DAS EMPRESAS}

As Empresas A e B são incorporadoras e construtoras consolidadas, com mais de 35 anos no mercado da região metropolitana de Florianópolis. A autora principal deste trabalho atuou profissionalmente nas duas empresas, sempre como engenheira civil na área de gestão de projetos. Nesse período a autora também auxiliou as empresas em seus processos de certificação da qualidade ISO e PBQP-H. Com base nesses processos de certificação da qualidade, aliado ao estudo do modelo de referência do processo de gestão de projetos (Romano, 2003); e ainda no mapeamento do processo da Empresa A (EA) e da Empresa B (EB) realizados, através de entrevistas com os profissionais envolvidos e a análise documental de toda a cadeia de projetos das empresas - tudo isto detalhadamente documentado na dissertação de mestrado de (Avila, 2010) - foram preenchidas as Tabelas 1 e 2. Neste artigo, por restrição de paginas, optou-se por apresentar com ênfase os resultados e reflexões sobre o diagnóstico realizado. 
Tabela 1 - Critérios para avaliação do processo de projeto

\begin{tabular}{l|c|c}
\hline \multicolumn{1}{c|}{$\begin{array}{c}\text { Processo de Projeto de Edificações } \\
\text { Elemento Analisado }\end{array}$} & EA & EB \\
\hline Formalização do Processo de Projeto & $\mathbf{5 , 5}$ & $\mathbf{3 , 5}$ \\
\hline Fases do Processo de Projeto & $\mathbf{4 , 0}$ & $\mathbf{4 , 0}$ \\
\hline Planejamento do empreendimento & $\mathbf{0 , 0}$ & $\mathbf{0 , 0}$ \\
\hline Desenvolvimento do projeto informacional & $\mathbf{2 , 0}$ & $\mathbf{2 , 0}$ \\
\hline Desenvolvimento do projeto informacional & $\mathbf{9 , 5}$ & $\mathbf{3 , 0}$ \\
\hline Desenvolvimento do projeto conceitual da edificação & $\mathbf{3 , 5}$ & $\mathbf{2 , 5}$ \\
\hline Desenvolvimento do projeto preliminar da edificação & $\mathbf{6 , 5}$ & $\mathbf{5 , 0}$ \\
\hline Desenvolvimento do projeto preliminar da edificação & $\mathbf{2 , 5}$ & $\mathbf{1 , 5}$ \\
\hline Acompanhamento do projeto legal da edificação & $\mathbf{1 , 0}$ & $\mathbf{1 , 0}$ \\
\hline $\begin{array}{l}\text { Desenvolvimento do projeto detalhado e dos projetos para produção } \\
\text { da edificação }\end{array}$ & $\mathbf{1 2 , 5}$ & $\mathbf{8 , 5}$ \\
\hline Acompanhamento da obra & $\mathbf{n / a}$ & $\mathbf{n / a}$ \\
\hline Acompanhamento do uso & $\mathbf{n} / \mathbf{a}$ & $\mathbf{n / a}$ \\
\hline Somatório do atendimento aos critérios analisados & & \\
\hline \% de atendimento de cada empresa em relação aos critérios & $\mathbf{4 7}$ & $\mathbf{3 1}$ \\
\hline analisados & $\mathbf{6 8 , 1 0}$ & $\mathbf{4 4 , 9 1}$ \\
\hline
\end{tabular}

Fonte: Adaptado de (Romano, 2003)

Tabela 2 - Critérios avaliação do gerenciamento de projetos

\begin{tabular}{l|c|c}
\hline \multicolumn{1}{c|}{$\begin{array}{c}\text { Processo de Gerenciamento de Projetos } \\
\text { Elemento Analisado }\end{array}$} & $\mathrm{EA}$ & $\mathrm{EB}$ \\
\hline Iniciação & $\mathbf{5 , 0}$ & $\mathbf{3 , 5}$ \\
\hline Planejamento & 10,0 & $\mathbf{5 , 0}$ \\
\hline Execução & 1,5 & 1,5 \\
\hline Controle & 1,5 & 1,5 \\
\hline Encerramento & $\mathrm{n} / \mathbf{a}$ & $\mathbf{n} / \mathbf{a}$ \\
\hline Somatório do atendimento aos critérios analisados & & \\
\hline $\begin{array}{l}\text { \% de atendimento de cada empresa em relação aos critérios } \\
\text { analisados }\end{array}$ & $\mathbf{1 8}$ & $\mathbf{1 2}$ \\
\hline
\end{tabular}

Fonte: Adaptado de (Romano, 2003)

O mapeamento da gestão do processo de projeto em cada uma das empresas leva a algumas reflexões. Muitos dos pontos aqui discutidos estão implícitos aos itens expostos nas Tabelas 1 e 2. O detalhamento dessas Tabelas é encontrado em (Avila, 2010).

Aprovação do plano de projeto: de acordo com o GPPIE, observando o diagnóstico feito por (Avila, 2010), as atividades pertencentes à etapa de plano de projeto não foram observadas nas empresas estudadas. Geralmente, a avaliação comparativa com imóveis disponíveis no mercado é realizada na definição do produto. Tão pouco é definido com antecedência o plano sumário do projeto, onde se teria a descrição do produto a ser desenvolvido, com a determinação de um cronograma preliminar do empreendimento ou mesmo a estimativa inicial dos custos do projeto;

Análise da viabilidade técnica e legal do terreno: conforme diagnóstico feito por (Avila, 2010), ambas as empresas avaliam a viabilidade técnica e legal dos terrenos antes da 
aquisição. As informações necessárias para esta avaliação são oriundas do levantamento topográfico, sondagem, e outros estudos físicos do terreno, além da consulta de viabilidade para construção. A consulta de viabilidade é fornecida pela prefeitura e informa o gabarito máximo permitido na área do terreno, a taxa de ocupação, e ainda se o uso ao qual se destina é adequado.

Definição das estimativas iniciais de custo: não foi observada nas empresas estudadas, a abordagem do levantamento de custos iniciais de elaboração de um projeto. As empresas não definem ou não preveem o quanto vão gastar durante a elaboração dos projetos de um empreendimento. Não há previsão de custos com impressões, por exemplo.

Os resultados apontados pelas planilhas devem ser avaliados mais pela ótica qualitativa da maturidade com que as empresas tratam a gestão e o processo de projeto de edificações, do que propriamente pelo foco quantitativo expresso pelos números. Os percentuais crus, $\mathrm{EA}=68 \%$ e $37,5 \%$; $\mathrm{EB}=45 \%$ e $25 \%$, representam o distanciamento das duas empresas com relação ao modelo de referência, estando na análise feita na Empresa A mais próxima. O resultado mais importante neste diagnóstico está relacionado aos sistemas de gestão da qualidade ISO 9000 e PBQP-h. A certificação das empresas nesses programas, apesar de exigirem o controle do desenvolvimento dos projetos de edificações em seus requisitos, não é garantia para o gerenciamento de um processo de elaboração de projetos eficiente. Entretanto, apresentam-se outras considerações a respeito deste diagnóstico e alguns fatores externos que influenciam as tomadas de decisão nas empresas estudadas:

A aquisição do terreno: o diagnóstico apresentado em (Avila, 2010) aponta que as duas empresas estudadas enfrentam dificuldades em planejar de forma prévia um empreendimento para, posteriormente, buscar um terreno com as características adequadas para implantar o empreendimento idealizado. A compra de um terreno transformou-se em um 'verdadeiro leilão', onde duas ou mais empresas disputam a preferência do proprietário do terreno. Normalmente, a empresa que consegue efetivar a aquisição do terreno é aquela que oferece a melhor oferta, aliando custo $\mathrm{x}$ benefício do projeto com a maior área construída no terreno. Além disso, plano diretor de Florianópolis, que determina as condições de uso e ocupação do solo, mapeou a cidade em regiões ou zonas com restrições a construção. Isso confere aos terrenos diferenciações relativas à taxa de ocupação e ao gabarito máximo permitido para cada área, por exemplo. Esses fatores influem diretamente no potencial construtivo de cada terreno. Ou seja, assim que surge um terreno, em uma determinada área que seja interessante ao empresário, o primeiro passo é fazer o levantamento dos parâmetros legais de construção (índices construtivos, altura máxima, afastamentos, entre outros) e um estudo preliminar da tipologia do produto, a fim de dar início à negociação de aquisição do terreno. O que ocorre também com frequência é a necessidade de aquisição de três ou até quatro terrenos em uma determinada região, que permita chegar a um potencial construtivo que permita a materialização do empreendimento. Uma postura que poderia vir ao encontro do melhor planejamento de um empreendimento seria a aquisição antecipada de novos terrenos. Nesse caso, a postura da empresa estaria voltada a elaboração do que se pode chamar de "banco de terrenos", visando o lançamento de novos empreendimentos em longo prazo.

A legislação vigente: a ocorrência de alterações na legislação vigente de maneira restritiva, como por exemplo, redução no gabarito máximo ou da taxa de ocupação do terreno, também foi um fator que provocou interferência na rotina das empresas estudas, contribuindo para a elaboração desordenada dos projetos. Geralmente essas alterações estabelecem prazos para a entrada em vigor, ou seja, as empresas que solicitarem a aprovação do projeto arquitetônico na prefeitura municipal até determinada data, o 
mesmo será analisado de acordo com as regras anteriores. Os demais, que solicitarem a aprovação do projeto após essa data, serão analisados conforme a nova legislação. Nesse caso, os empresários que possuem terrenos adquiridos nas áreas atingidas, optam por transpor etapas, desenvolvendo os projetos sem qualquer controle ou organização, para evitar que haja prejuízo financeiro quando da execução do empreendimento.

A contratação da equipe de projetistas: um problema que as duas empresas estudas enfrentam muitas vezes, é a falta de mais opções de profissionais de projeto no mercado de Florianópolis para desenvolver os projetos de edificação. Começando com o arquiteto que muitas vezes vem "pendurado" ao terreno por ter, de alguma forma, contribuído para a efetivação da compra do terreno. Em resumo, não há propriamente a seleção dos profissionais e das melhores propostas técnicas a serem contratados para desenvolver os projetos de edificações para as empresas. Entretanto, há de ser ressaltado que essa situação é resultado do comportamento das empresas de construção e incorporação contratantes dos serviços de engenharia. Muitas vezes, elas são resistentes em buscar novos parceiros de trabalho, muito em função da comodidade de não precisar explicar ou "ensinar" a novos fornecedores de projeto a maneira como a empresa quer que os trabalhos sejam desenvolvidos. Isto coloca a equipe de projetos numa posição confortável, num ambiente sem concorrência pelo melhor prestador de serviço. A consequência desta postura é a inversão da relação contratante e contratada: os projetistas acabam por ignorar as solicitações e especificações definidas pelos contratantes.

A definição do produto: dentre as etapas determinantes do sucesso de um empreendimento, a principal passa pela definição do público alvo e pela identificação das necessidades ou características desejadas por estes clientes, quando da aquisição de um residencial ou comercial. Uma ferramenta que auxilia na determinação dos requisitos de projeto e programa de necessidades, direcionados ao publico alvo é a pesquisa de mercado e o briefing de oferta. Entretanto, o que se pode perceber é que poucas empresas realizam o estudo de mercado como auxilio na definição do produto a ser lançado, e quando o fazem, talvez não utilizem a melhor metodologia para tal.

Das empresas estudadas, apenas a empresa A possui uma estrutura direcionada a promoção dos empreendimentos concretizada no departamento de marketing que também tem por responsabilidade auxiliar na identificação da demanda de mercado. Ainda assim, dificilmente a empresa vai buscar em suas pesquisas características relativas a métodos construtivos, tamanho de compartimentos, ou mesmo a racionalidade construtiva. Quando existem dúvidas na definição do produto muitas vezes a pesquisa elenca apenas os dados relacionados à infraestrutura dos empreendimentos oferecidos pela concorrência. Se ainda assim houver dúvida quanto à tipologia definida, procede-se a consulta de opinião dos possíveis usuários apresentando a planta da edificação, e registrando suas impressões, inclusive em relação aos equipamentos da área comum.

Definido o produto, ele é formalizado pelo registro dos requisitos de projeto e do programa de necessidades, permitindo que a empresa possa verificar o desempenho do empreendimento ao final da obra. Nessa avaliação a empresa tem a oportunidade de conferir quais dos requisitos cumpriram ou não o desempenho desejado, permitindo que os requisitos não satisfatórios sejam melhorados nos próximos empreendimentos.

A coordenação do processo: a coordenação do processo de projeto de edificações tem por objetivo a garantia ao atendimento dos requisitos exigidos pelo cliente, o controle e o fluxo de informações entre os participantes e a compatibilidade entre as soluções dos sistemas projetados. Nesse contexto, o coordenador ou do gerente de projeto exerce 
papel fundamental na administração do processo de projeto. Conforme apontado no diagnóstico em (Avila, 2010), tanto a empresa A quanto a empresa B possuem profissionais em seu corpo técnico designados a desenvolver as atividades inerentes a coordenação do processo de projeto. Os resultados dos estudos confirmam o que foi visto anteriormente, onde vários autores apontam as vantagens e desvantagens das diferentes modalidades de coordenação de projeto, onde o coordenador pode ser: um arquiteto ou um escritório de arquitetura, estar ligado à construtora ou ser um consultor externo contratado pela empresa. O estudo das empresas A e B mostra que o coordenador de projeto necessariamente tem que estar dentro da empresa, com algumas ressalvas. Os profissionais designados a desempenhar o papel de coordenador ou gerente de projetos não deveriam acumular outras funções dentro da empresa a exemplo do que ocorre na empresa $\mathrm{B}$, onde o gerente técnico desempenha também as funções de coordenação e compatibilização de projetos. $O$ acumulo de funções compromete a eficiência do processo, fato comprovado pela diferença de desempenho entre as empresas A e B. O coordenador também não pode ser o arquiteto ou o escritório de arquitetura, já que na maioria das vezes ele é contratado para desenvolver o projeto. Isso influi diretamente na imparcialidade do processo de coordenação e compatibilização do projeto do empreendimento. $\mathrm{O}$ arquiteto tem dificuldade para materializar as especificações e requisitos de projeto solicitados pela empresa. Na maioria das vezes esses dados de entrada são restritivos em relação ao processo de criação, indo de encontro ao desejo que o profissional ou escritório de arquitetura tem de deixar sua marca registrada nos empreendimentos da empresa. Outra opção seria a contratação de um consultor experiente para coordenar e compatibilizar os projetos dentro da empresa, mas o mercado da construção e incorporação em Florianópolis no momento não absorveria tal profissional. Acredita-se que a maior parte das empresas ainda não assimilou ou desenvolveu uma cultura voltada ao controle e a qualidade do processo de projeto. Além disso, há a resistência em revelar a um profissional externo à empresa os procedimentos internos relacionados a padronizações, procedimentos executivos e qualquer outra informação de propriedade intelectual da empresa.

A coordenação do processo de projeto exige do profissional que irá desempenhar essa função, entre outras atividades: administrar a troca de informações entre a equipe interna e externa de projeto; conduzir reuniões de coordenação e análise crítica dos projetos; receber, controlar e aprovar o desenvolvimento dos projetos contratados durante todo o processo. Para tanto o mercado já coloca à disposição das empresas ferramentas gerenciais eficientes que auxiliam o gerente e o coordenador de projetos a controlar todo o processo de desenvolvimento do projeto de edificações. Citam-se como exemplos o aplicativo 'Autodoc' e o sistema 'Construtivo', esse adotado pela empresa A. A opção pelo uso de sistemas on-line pelas empresas proporciona a convergência das informações de projeto num ambiente único, podendo ser acessado pela equipe de projeto em qualquer lugar e a qualquer hora. Outra vantagem é o maior controle sobre prazos, entrega de documentos, liberação de etapas, controle dos documentos gerados e dos itens acessados, por exemplo.

Entretanto, os sistemas colaborativos não dispensam a reunião periódica com a equipe de projeto. Normalmente não há a definição antecipada de um cronograma periódico das reuniões com os projetistas. Elas ocorrem conforme a necessidade. No início do processo para apresentar o escopo de cada especialidade individualmente a cada projetista. A prática vivenciada na empresa A mostrou que as reuniões individuais com cada projetista eram mais produtivas nas discussões relativas a soluções de projeto e esclarecimento de dúvidas. Durante o processo de desenvolvimento do projeto as 
reuniões geralmente ocorrem após o período de compatibilização dos projetos. Nessa fase, as reuniões tem como objetivo apresentar os resultados da análise crítica, verificações de incompatibilidades do projeto e definir o prazo de entrega das correções solicitadas aos projetistas envolvidos na etapa. A experiência vivenciada na empresa A também mostrou que reuniões multidisciplinares com muitos profissionais de diferentes disciplinas de projeto envolvidos no processo são pouco produtivas e inconclusivas. Isto porque os participantes que não estiverem envolvidos na discussão acabam dispersando o foco da reunião com conversas paralelas e desatenção ao que está sendo discutido.

O processo de elaboração dos projetos: outra razão pela qual se acredita que a grande parte das empresas ainda ignora ou não dá a devida atenção e importância aos benefícios que a coordenação e compatibilização podem trazer é que o desenvolvimento dos projetos acontece à revelia do presidente da empresa. Dificilmente as incompatibilidades, a falta de informação e de detalhamento dos projetos que acabam refletindo em problemas durante a execução da obra chegam ao conhecimento da presidência da empresa. Normalmente tudo é decidido e solucionado pelo engenheiro da obra em conjunto com o superior imediato, no caso o diretor ou o gerente técnico. Este fato foi observado nas duas empresas estudadas.

Conforme o diagnóstico realizado (Avila, 2010), entrevistas e documentos, a empresa A e a empresa B tratam o processo de projeto de maneiras bastante opostas. Na primeira temos e elaboração do projeto de edificações feito em etapas, evoluindo de acordo com a complementação das informações nas diferentes fases do desenvolvimento. As entradas, saídas de projeto, resultado das verificações e análise crítica são registradas em documentos próprios e padronizados. A compatibilização ocorre ao longo do desenvolvimento das etapas do processo de projeto. No outro extremo, tem-se o processo de projeto bem simplificado da empresa B. De maneira geral os projetos são desenvolvidos de maneira informal, não há pesquisa de mercado, formalização do programa de necessidades e requisitos de projeto. O resultado das verificações de projeto e análise crítica ficam registrados nas próprias folhas do projeto e os itens analisados acabam se perdendo junto com o material quando ele é descartado. Os projetos são compatibilizados apenas quando estão completamente finalizados, quando as disciplinas de projeto são sobrepostas em cores diferenciadas, permitindo apenas identificar as incompatibilidades por sobreposição entre os sistemas, deixando de avaliar se a solução de projeto proposta pelo projetista é a mais adequada ao resultado que se pretende.

O detalhamento dos projetos: de maneira geral, conforme o diagnóstico feito, nas duas empresas os projetos não são detalhados como deveriam, muito em virtude da pouca exigência ou falta de interesse das empresas. O projeto elétrico, por exemplo, não contempla as furações de lajes e vigas, e tão pouco as cotas de amarração vertical e horizontal dos pontos elétricos nos ambientes. O leque de atividades que podem ser detalhadas a fim de facilitar o dia a dia de uma obra é imenso. Iniciando pelo detalhamento sugerido pelo GPPIE com a elaboração do projeto do canteiro de obras, de formas e escoramento, de alvenarias de vedação e revestimentos, podendo estender ao projeto de impermeabilização, padronização dos detalhes executivos de juntas dilatação nas fachadas, entre outras possibilidades. As empresas não têm a cultura de projetar o canteiro de obras. Geralmente o próprio engenheiro da obra desenha um esboço das instalações provisórias de acordo com a geografia do terreno e define os locais de estocagem dos materiais. Após o início da obra, assim que possível o canteiro de obras é deslocado para dentro da edificação. A empresa A costuma contratar uma empresa para fazer seu projeto de formas. Entretanto o detalhamento de projetos voltados à execução da obra não avança muito além disso. Um dos pontos fortes da empresa $\mathrm{B}$, apesar da 
forma simplificada e pouco controlada com que desenvolve seus projetos, é a elaboração do projeto executivo compatibilizado. Como visto anteriormente trata-se de um projeto com as disciplinas de projeto sobrepostas em cores diferenciadas, mas com cotas e detalhamento executivo das instalações prediais e de locação de alvenaria.

O gerenciamento do projeto de edificações: o diagnóstico feito por (Avila, 2010) indica que não é habito entre as empresas estudadas a elaboração de um orçamento para as atividades de projeto. Algumas das justificativas já foram expostas ao longo deste capítulo. Entretanto, se bem aplicada, essa seria uma ferramenta importante dentro do processo de projeto nas empresas. Na maneira como os contratos de engenharia são assinados hoje, a empresa não tem referencial para avaliar de forma mais efetiva a proposta comercial dos parceiros de projeto. O gerente de projeto ou o responsável pelas contratações dos serviços de projeto não dispõe de subsídios para analisar se o valor que está sendo solicitado para a execução dos serviços é justo, já que não há base para comparação com propostas elaboradas para empreendimentos similares anteriores. A orçamentação da etapa de projeto poderia ser adotada como um indicador de avaliação dos fornecedores de projeto. Por outro lado questões como, por exemplo, a alocação de recursos físicos não apresenta aplicação ou vantagem explícita para justifique tal planejamento. Em geral, as empresas com equipe técnica constituída dispõem aos colaboradores a infraestrutura necessária ao pleno desenvolvimento de suas atividades, como computadores, normas técnicas, entre outros. De maneira geral, a parte gerencial do projeto também é bastante negligenciada nas empresas. O cronograma de trabalho se resume apenas ao acompanhamento do andamento das atividades de projeto, num comparativo simples entre o que foi planejado e o que foi realizado. Os contratos com fornecedores de projeto são firmados por remuneração após a entrega das etapas de projeto (estudo preliminar, anteprojeto, projeto legal) sem qualquer vínculo direto relacionado a um cronograma físico-financeiro da elaboração dos projetos, por exemplo.

\section{CONSIDERAÇÕES FINAIS}

Este artigo teve como objetivo avaliar a gestão do processo de projeto em duas empresas de construção e incorporação de imóveis em Florianópolis. Os resultados apontaram que a empresa A é a que mais se enquadra dentro das premissas propostas pelo GPPIE (Romano, 2003). Mas a cultura voltada a projetos para produção em obra adotada pela empresa B, mesmo que ainda se apresentem de forma simplificada, não pode ser ignorada. Pelo panorama do mercado da construção imobiliária em Florianópolis, uma das primeiras conclusões é que os processos de projeto de edificações das empresas A e B são complementares. Nesse sentido, incorporando os projetos voltados à produção em obra da empresa B ao processo de projeto de edificações da empresa A, seria o suficiente para iniciar o processo de amadurecimento da organização, na direção de um sistema de controle e padronização do processo de projeto como preconiza o GPPIE. Dessa forma, acredita-se que esse também seria um bom ponto de partida para as empresas que desejam introduzir em sua rotina os preceitos da coordenação e compatibilização dos projetos de engenharia. Isto porque, o processo de projeto de edificações na empresa A foi estruturado de acordo com a realidade de atuação da empresa dentro no mercado imobiliário de Florianópolis e aborda muito dos conceitos apresentados neste trabalho. Existem muitos fatores para a divergência na implantação de modelos de gestão e coordenação no cenário das empresas estudadas. As principais talvez sejam: a) A metodologia usada como referência não foi concebida para todos os tipos de empresas, então o modelo deve ser adaptado. Por exemplo, a compra do terreno não pode ser definida após a elaboração dos projetos de engenharia. Os projetos da futura edificação 
devem ser elaborados de acordo com o potencial construtivo do terreno já adquirido; $b$ ) As empresas de uma maneira geral, estão sujeitas às oscilações do mercado, criadas pela necessidade de adaptação, em função de interferências externas (projetistas, clientes, financiadores, legislação, entre outros). Acrescenta-se ainda que exista o descaso e, consequentemente, a falta do conhecimento de boa parte dos colaboradores das empresas (e dos demais envolvidos), na real importância de um processo organizado de gestão e coordenação de projetos. No entanto, os critérios relacionados ao processo e ao gerenciamento do projeto de edificações aplicados nas empresas A e B, e os respectivos resultados, apontam em outra direção: talvez os referenciais acadêmicos possam sim melhorar o desempenho das empresas de construção e incorporação de imóveis. Desde que o cenário onde as empresas atuam não seja ignorado. Os resultados também apontam que as duas empresas ainda estão distantes do que se pode considerar ideal em termos de gerenciamento do processo de projeto. Os cronogramas são bastante simplificados e não permitem uma avaliação mais apurada do andamento do projeto. Ou seja, se houver atraso na entrega de alguma das etapas de projeto, o prazo é simplesmente postergado, sem que haja uma análise de comportamento ou o remanejamento de outras atividades para que não haja o comprometimento do cronograma definido anteriormente. Outra ferramenta de grande utilidade é a orçamentação e a determinação dos custos relativos ao processo, como por exemplo, o controle de gastos com impressões. As empresas não têm controle algum sobre custos gerados a partir das atividades de projeto. Não há como acompanhar efetivamente aquilo que não se conhece, e por vezes o custo meta da edificação não é atingido. As possibilidades e ferramentas para gerenciamento do processo são vastas, entretanto, o projeto ainda não é encarado como um dos fatores principais responsáveis pelo sucesso de um empreendimento. Como conclusão, afirma-se que o trabalho alcançou o seu propósito: a análise e discussão da gestão do processo de projeto em duas empresas de construção e incorporação de Florianópolis. Ficam como contribuições principais: a apresentação da rotina de projeto nas empresas estudadas; as reflexões sobre os entraves enfrentados pelas empresas estudadas, e que exercem influência direta na maneira como essas empresas desenvolvem o processo de projeto de edificações.

\section{REFERÊNCIAS}

ADESSE, E. \& MELHADO, S. B. A Coordenação de projetos externa em Empresas Construtoras de Pequeno e Médio Portes. In: SIMPÓSIO BRASILEIRO DE GESTÃO E ECONOMIA DA CONSTRUÇÃO, 2003. Anais.... Belo Horizonte: UFMG.

AVILA, T. C. F. Gestão de Projetos na Construção Civil: Avaliação do processo em duas empresas construtoras de Florianópolis. 2010. 112f. Dissertação (Mestrado em Engenharia Civil) - Programa de Pós-Graduação em Engenharia Civil, UFSC, Florianópolis.

BRASIL, P.; SALGADO, M.; LOMARDO, L. Entraves na gestão do processo de projeto de edificações públicas: uma análise da lei 8.666/93. In: SIMPÓSIO BRASILEIRO DE QUALIDADE DO PROJETO NO AMBIENTE CONSTRUÍDO, 3., 2013. Anais.... São Paulo: ANTAC.

MANZIONE, L. Proposição de uma estrutura conceitual de gestão do processo de projeto colaborativo com o uso do BIM. 2013. 325f. Tese (Doutorado em Engenharia Civil) Escola Politécnica, USP, São Paulo.

MELHADO, S. B., Coordenação de projetos na construção de edifícios. In: WORKSHOP QUALIDADE E COORDENAÇÃO DE PROJETOS, 1998. Anais.... São Paulo: EPUSP.

ROMANO, F. V. Modelo de referência para o gerenciamento do processo integrado de edificações. 2003. 326f. Tese (Doutorado em Engenharia de Produção) - Programa de PósGraduação em Engenharia de produção, UFSC, Florianópolis. 